\title{
Mechanical mastication thins Lake Tahoe forest with few adverse impacts
}

\author{
by B. Hatchett, Michael P. Hogan \\ and Mark E. Grismer
}

\section{An overstocked montane, mixed-} conifer forest on the west shore of the Lake Tahoe Basin was thinned using a Fecon masticator, leaving woodchips and tree shreddings on-site as mulch. No significant differences in soil compaction were found in 13 of 15 comparisons of soil-profile resistance values at several distances from the machine track and varying depths. We then watered the mastication sites with a rainfall simulator, and measured runoff, infiltration and erosion. The treatments included woodchipcovered and bare-soil plots corresponding to mulched track, as well as native grass, bare soils and relatively undisturbed soil plots. Sediment yields were greatest from the bare soils, followed by the undisturbed, grass and woodchip plots. Mastication appears to be an effective thinning treatment for overstocked forests with few discernible negative impacts on soil compaction or lake-polluting runoff.

$\mathrm{F}$ rest health, wildfire prevention and water-quality protection are interrelated environmental issues in the Lake Tahoe Basin and throughout the western United States. Overstocked forests are largely the result of fire suppression during the past 100 years by federal, state and private land-management agencies. Managers are now faced with forests of higher density and a high incidence of insect- and stress-related tree die-off, resulting in increased fire potential and disease transmissibility.

Fires in these overstocked stands tend to be high-intensity "scouring" fires, which leave little intact understory and sterilize the soil. Loss of cover leaves bare soils extremely prone to erosion,

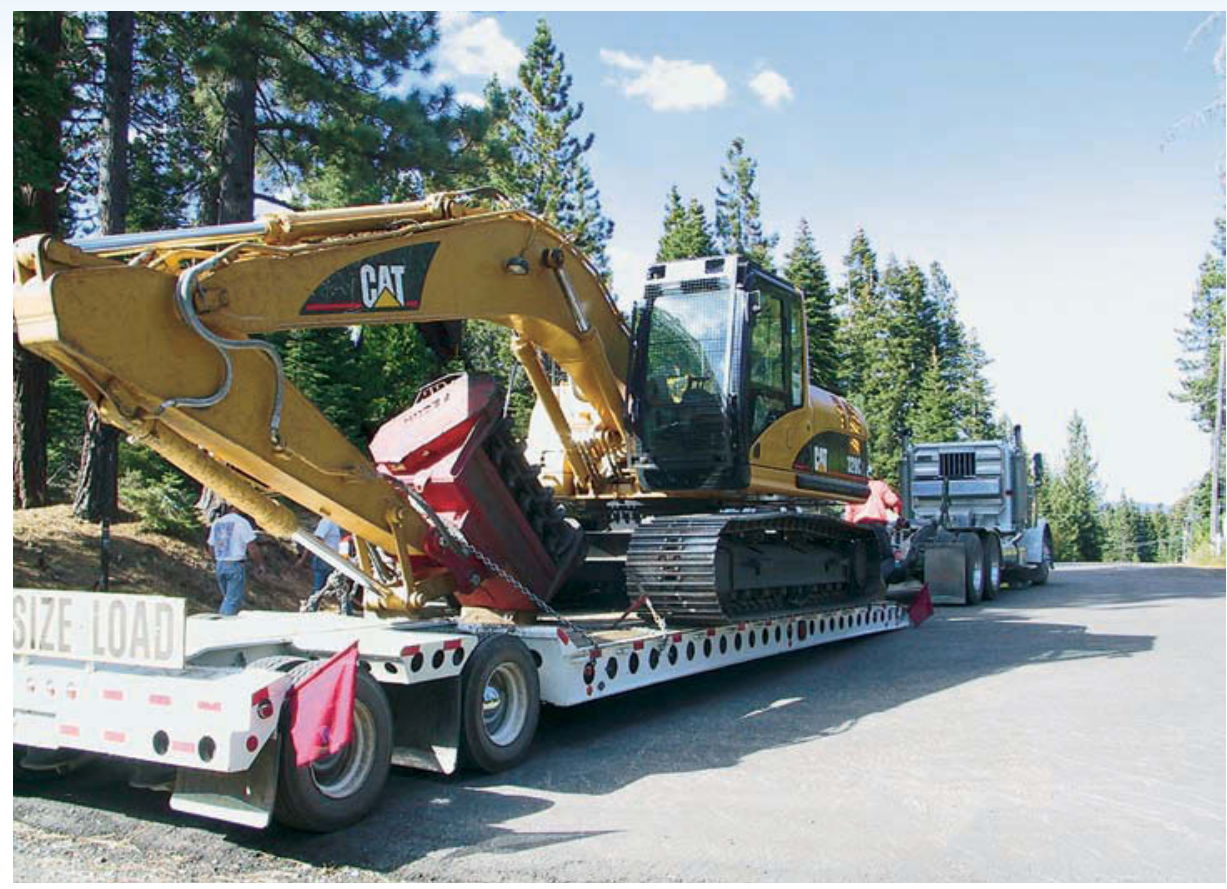

Mechanical mastication is a promising method for thinning overstocked forests. Above, a Fecon Bull Hog BH 80 masticator head is mounted to the boom of a Caterpillar 235 excavator.

negatively affecting downstream water quality. To address these concerns, such forests are thinned by reducing standing biomass in the understory, reducing the density of timber stands, or both. A less common but promising method is employing a mechanical masticator to potentially address forest health, fire prevention and water quality. A mechanical masticator is similar to a wood chipper; it is mounted on an excavator-type crawler tractor, which moves through the forest to chip or shred trees and brush, leaving the woodchips behind. However, the environmental costs and benefits of treating forests with mechanical masticators have not been adequately studied.

\section{Factors contributing to erosion}

Considerable research has been conducted on the factors contributing to soil compaction and erosion in forest soils. Nolte and Fausey (1986) reported that if soil compaction (cone penetrometer resistance) doubles, water infiltration rates can decrease by a factor of ten. Wall et al. (1987) and Frisby and Pfost (1993) noted that decreased infiltration and increased runoff may result from compacted subsurface soil layers. Infiltration is a key variable in erosion because it regulates the amount of runoff entering the soil. The greater the relative infiltration, the lower the runoff rates and thus the lower potential erosion from a site (Radcliffe and Rasmussen 2000).

Imeson and Lavee (1998) examined the influence of temporal and spatial scales on erosion processes, and found that soil aggregate stability - the cohesive structure holding together individual soil particles - was a key indicator of erosion. Greater aggregate stability results in greater infiltration rates and increased resistance of aggregates to shear detachment, or breakup, thereby reducing erosion. Aggregate stability is controlled by the extent of shading (vegetation and litter coverage), organic matter dynamics (the turnover of organic matter, and root production) and slope angle and aspect (which direction it faces, such as north, south, etc.).

Plant cover is critical for controlling erosion. Trees and dense grasses can reduce erosion by $70 \%$ when compared to bare soil (Bonan 2002). Allred (1950) reported that rain-fed infiltration rates decreased drastically with reductions in vegetation cover and organic matter. 


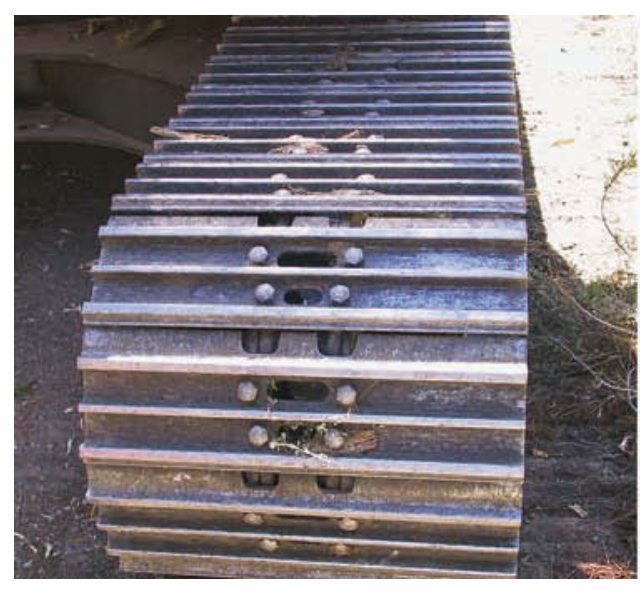

Right and center, the masticator grinds overstocked forest understory and leaves a layer of protective mulch. The authors evaluated whether the large machine's tread, left, contributes to soil compaction and subsequent runoff.

Plant and litter cover protects the soil from raindrop impact and splash, tends to slow down the movement of surface runoff, and increases the infiltration rate and water-holding capacity of the soil (Wall et al. 1987; Molinar et al. 2001).

In forests, the factor used to estimate total erosion losses decreases from 0.36 on soils with no litter cover to 0.003 with $100 \%$ litter cover (Bonan 2002). Soils covered by vegetation or litter generally have high levels of aggregate stability, as do soils with favorable organic-matter contents. Litter cover also lowers the evapotranspiration rate from moist soils and reduces soil temperatures relative to bare soils, improving microbial soil habitats and enhancing grass-seed germination and establishment (Molinar et al. 2001). Slope angle is also important to both aggregate stability and erosion rates, depending on the aspect and initial stability of the soil. For example, on south-facing slopes, soils with low aggregate stability or low infiltration capacity tend to be more erosion prone than those on north-facing slopes, especially in the Sierra Nevada of California.

\section{Benefits of forest thinning}

Excess cover, however, especially in an overstocked forest, can create extreme fire danger and catastrophic results for the forest habitat and surrounding human habitation. Overstocked forest stands are thinned in numerous ways. Forest thinning involves removing small to medium-diameter trees and shrubs, which opens the canopy and forest floor and provides the remaining stand with
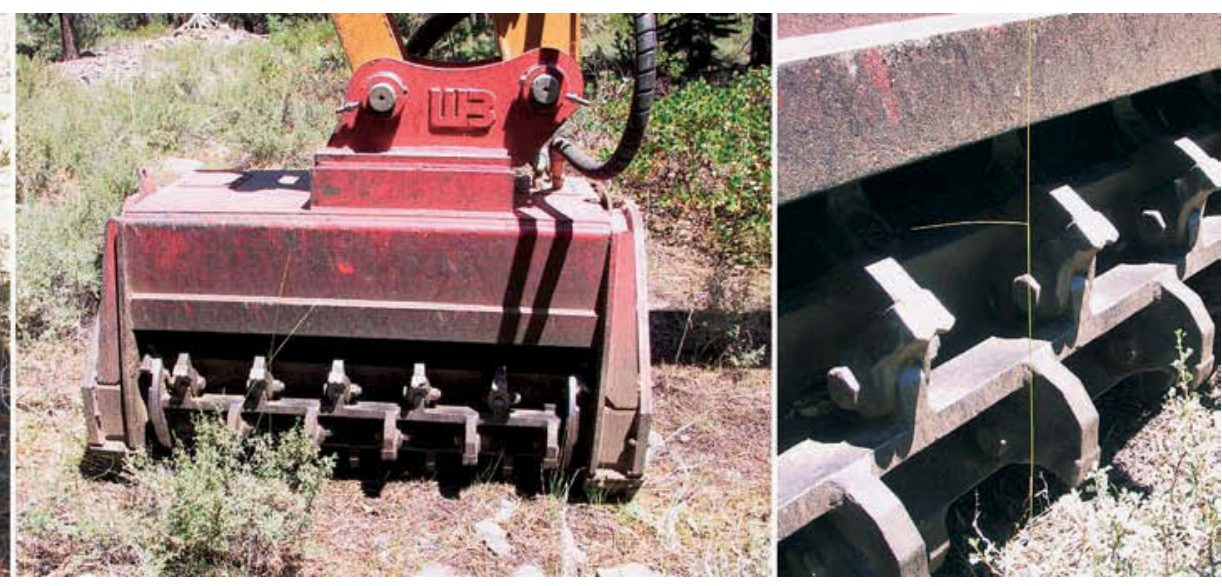

access to more nutrients, sunlight, water and space. The thinned stand tends to grow with increased vigor and health, resulting in improved biodiversity of flora and fauna and better overall appearance. At the same time, less fuel is available for wildfires and the threat of crown fires is reduced. Open canopies also allow a greater accumulation of snow on the forest floor, leaving more water for both the ecosystem and human consumption upon melting (Bowling et al. 2000).

Methods of forest thinning include crews that hand-thin using chainsaws and then burn or chip the slash (branches and trimmings left after removing tree trunks for firewood), to mechanized thinning using heavy machinery such as the masticator. Burning may have the greatest implications environmentally and socioeconomically. Concentrated, intense heat from burn piles can sterilize nearby soil through the combustion of nutrients and organic matter. In addition, the generated smoke and ash reduce air and water quality, and result in local complaints about health and other quality-of-life issues. Furthermore, burn piles have the potential to become uncontrolled and result in large-scale wildfires, which occurred in the 2000 Cerro Grande Fire near the Los Alamos National Laboratory in New Mexico.

\section{Mastication of fir tree stand}

The purpose of our study was to determine if heavy mastication equipment used for stand-density reduction in an overstocked forest would increase soil compaction and, subsequently, runoff and erosion. The study site was on the west shore of Lake Tahoe near Tahoma and consisted of an overstocked, fir-dominated, secondgrowth forest on a soil derived from mixed granite and volcanic material common to the area. Soils at the site were mapped as Tallac-series gravelly coarse sandy loam (Inceptisol order as a loamy skeletal mixed Entic Cryumbrept) derived from glacial outwash deposits of basic and metamorphic rock (Rogers 1974). This soil series is moderately well drained with a weakly cemented silica layer at a depth of approximately 40 inches ( 1 meter). Tahoma is situated at the border be-

[after mastication] is not highly localized, but is dispersed over a large distance.

tween volcanic, primarily andesitic rock to the north and granitic rock to the south.

The study site is typical of many west shore forests logged more than 100 years ago (Wilson 1992; direct ring counting of cut trees in 2004). Subsequent to initial logging in the late 19th century of what was then a pine-dominated forest, red and especially white fir trees (Abies magnifica and Abies concolor, respectively) regrew first and became the dominant species. After the U.S. Forest Service acquired much of the land in the 1960s and 1970s, fires were routinely suppressed and logging was discontinued.

In the project area, white and red fir make up over $90 \%$ of the stand, with the remainder comprised of Jeffrey pine (Pinus jeffreyi) and incense cedar (Calocedrus decurrens). Understory is relatively nonexistent in much of the area except where canopy openings occur; in these places there is a dense covering of golden chinquapin (Chrysolepis sempervirens), whitethorn (Ceanothus cordulatus) 


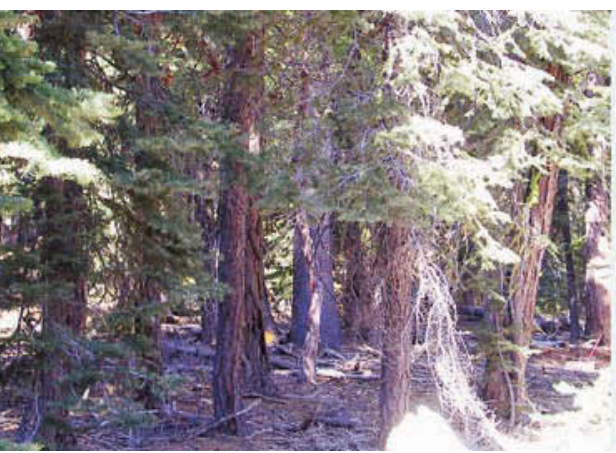

and greenleaf manzanita (Arctostaphylos patula) mixed with scattered forbs and grasses. Perhaps due to fire suppression, the forest floor was covered with at least 2 inches ( 5 centimeters) of needle litter, duff and other woody debris. In some areas, the mulch-duff layer was as much as 4 inches (10 centimeters).

Prior to treatment, the average actual stand density was as high as 2,020 stems per acre (5,043 stems per hectare) with an associated average canopy cover of $96.7 \%$. Mean stem diameter at breast height (about 4 to 5 feet) was 5.7 inches (14.5 centimeters). (Following mastication treatment, the average stand density was 279 stems per acre [696 stems per hectare] or $13.8 \%$ of the original density; the associated average canopy cover after treatment was $25.7 \%$ but ranged from $6 \%$ to $31 \%$.)

We thinned several acres of the study site with a Caterpillar 320C excavator equipped with low-ground-pressure (37.9 $\mathrm{kPa}$ or $5.5 \mathrm{psi}$ ) triple cleat grousers and a Fecon Bull Hog BH 80 masticator head. The use of low-ground-pressure machinery is believed to minimize shortterm compaction and eliminate longterm impacts such as soil compaction and increased runoff.

The boom-mounted head was capable of reaching to approximately 30 feet (10 meters) laterally/horizontally and vertically from the excavator, so that the excavator did not get too close to individual trees. The Fecon masticator head utilizes a rotating cylinder with fixed cutting teeth that "chew" the forest material into mulch, which is then deposited on the forest floor. No burning is required for mastication, as all of the fuels are converted to small pieces, generally less than handsized, and left as a protective mulch layer.

However, the use of heavy machinery in the forest may result in soil compaction at the machine tracks and the establishment of an unintentional "trail" that lasts
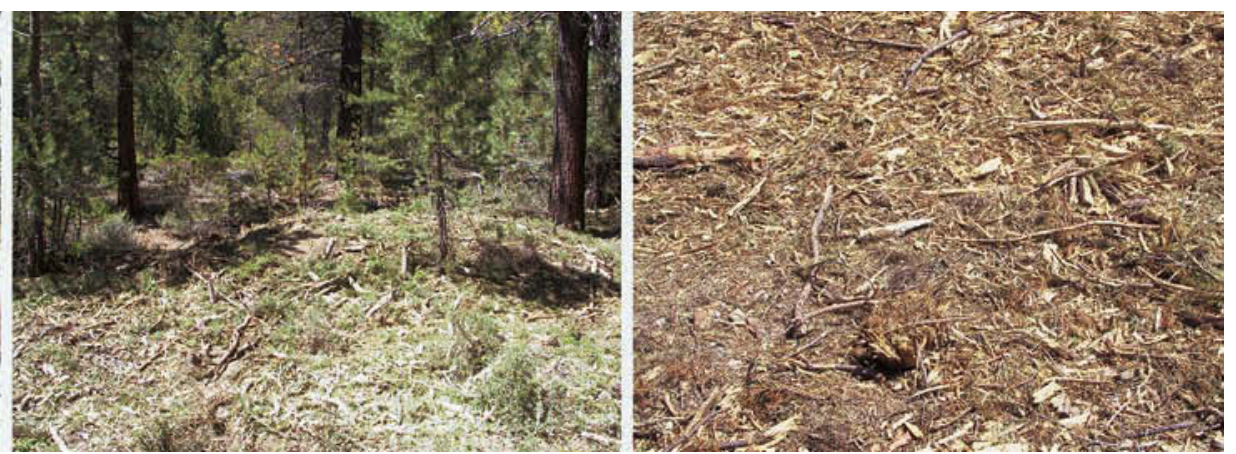

The study area in Tahoma, near Lake Tahoe, left before and, center, after mastication treatment; right, the masticator grinds forest material into hand-sized chunks.

took place in October 2004; soils tend to be driest in the fall - with gravimetric moisture content less than $10 \%$ - resulting in less possible soil compaction. In addition, during mastication the operator was careful to minimize soil disturbance by steering the machine as straight as possible, with no pivot turns at any time and all turns made in as broad an arc as the terrain and surrounding timber allowed. Mastication also enables established tracks to be covered by mulched litter, thereby reducing bare-soil exposure and, in turn, erosion.

\section{Measuring mastication impacts}

Following mastication of the larger project area, we designated 12 rainfall simulation plots to determine infiltration and runoff rates located on three transect lines, along which soil compaction measurements were taken (fig. 1). The transect lines extended 50 feet (15.2 meters) perpendicular from the middle of the excavator track and were 20 feet (6.1 meters) apart, yielding a total study area of approximately 2,000 square feet (0.019 hectare).

Soil compaction. Measurements were taken in late June 2004, when sufficient soil moisture was present for an accurate test of potential compaction. A cone penetrometer was used to measure resistance to force in pressure units as an index of soil compaction. A Spectrum Fieldscout SC 900 soil cone penetrometer (0.5-inch diameter [ 1.3 centimeters] and $30^{\circ}$ angle) with a data logger was used to measure resistance to a depth of 18 inches (46 centimeters). Recordings of the force required to insert the penetrometer in $\mathrm{kPa}$ (psi) were taken at 1-inch (2.5-centimeter) intervals at a maximum insertion rate of 1 inch ( 2.5 centimeters) per second. Soil strength was measured in each of five points located randomly along the excavator tracks.
Measurements were taken along each transect at 10-foot (3-meter) intervals, and at 10-foot (3-meter) intervals between transects along the machine track. Following Landsberg et al. (2003), we omitted all penetration values greater than five times the standard deviation of the mean resistance or greater than $3,400 \mathrm{kPa}$ (500 psi) at a given depth for each respective transect, under the assumption that excessive pressure was used to penetrate rocks, root systems or thick organic matter decomposing below the surface.

Soil compaction is more directly measured through the collection of predetermined soil sample volumes that are dried and weighed in the laboratory. Unfortunately, this fixed-volume sampling method is very difficult, if not impossible, in loose soils. As such, soil bulk-density samples were not collected due to funding constraints as well as sampling problems experienced by Munn (1998) in a similar study conducted several miles south of our project area.

Ground coverage and density. We recorded field notes about each transect and

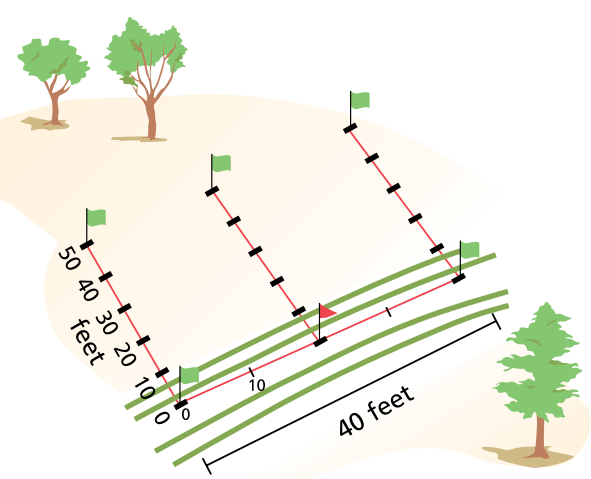

Fig. 1. Typical measurement plot and transect layout relative to excavator tracks (green lines). 
TABLE 1. Mean and standard deviation of penetrometer resistance values $(\mathrm{kPa})$ at distances from mastication track

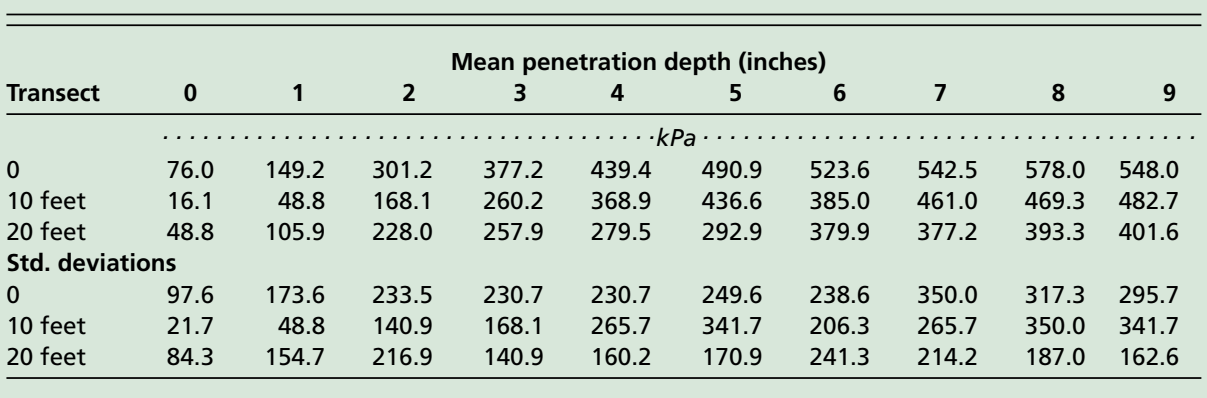

ocular estimates of the percentage bare ground on and off the mastication track. Overall stand density and changes in skyview factor - the amount of sky visible through the canopy when viewed from the ground - were also noted using visual estimation following Bonham (1989).

Cover-point monitoring techniques (Elzinga et al. 1998) were used to determine the extent of exposed soil along overlaying transects (Crocker and Tivner 1948; Bonham 1989; Hogan 2003). Three 100-foot (30-meter) transects were surveyed, with five points sampled per transect for a total of 150 measurements each. Transects were surveyed in four areas: a track where mulching occurred, a track where no mulching occurred, a relatively undisturbed "native grass" area to acquire estimates of exposed soil in the tracks, and an undisturbed area.

Rainfall simulation. Following the cone penetrometer and cover-point monitoring measurements, a rainfall simulator was used to determine infiltration, runoff and erosion rates from bare, native grass and mulched track soils (Battany and Grismer 2000; Grismer and Hogan 2004). The 12 rainfall-simulator plots corresponded to the penetrometer measurement locations in the mulched track and were 10 to 20 feet ( 3 to 6 meters) from the tracks. Due to access constraints, we used the "midget" rainfall simulator, which has a 3-foot (1-meter) fall height (compared to 12 feet $[3.5$ meters] for the full-size rainfall simulator). Because the kinetic energy of rainfall generated by the midget rainfall simulator is approximately $30 \%$ less than that of the full-size rainfall simulator, a rainfall intensity of about 3 inches (73 millimeters) per hour was used, as compared to the 2.35 inches (60 millimeters) per hour used in previous studies (Grismer and Hogan 2004). On three of the plots, a rainfall intensity of 4.7 inches (120 millimeters) per hour was applied to de- termine if greater intensity would affect sediment concentrations and yields.

Prior to rainfall simulation, a handheld moisture meter (a time domain reflectometry [TDR] probe) was used to measure pre-rainfall soil moisture at several locations in each plot. Rainfall was allowed to continue until either steady runoff was obtained or about 30 minutes had elapsed. Following field measurements, collected runoff samples were taken to the laboratory for filtration to determine sediment and organic matter content (Eshel et al. 2004).

\section{Little impact on soil compaction}

The penetrometer data was statistically evaluated using a paired $t$-test to compare resistance measurements for varying distances from the track at similar depths. The null hypothesis was that there would be no difference in penetration resistance for a given depth at varying distances from the track. The null hypothesis was rejected at $t$ values greater than absolute-value 2.00 and $P<0.05$ (95\% confidence) (tables 1 and 2). Depths of 0 and 1 inch ( 2.5 centimeters) were not analyzed because surface depth measurements were inconsistent due to instrumentation uncertainties; although these inconsistencies were much less prevalent at the 1-inch (2.5-centimeter) depth, they did still occur with enough frequency to render the data unreliable. Penetration resistance increased with depth, and values were $58 \%$ greater at the 4 -inch (10-centimeter) depth than at the 2-inch (5-centimeter) depth across all measurements. At a given depth, penetration resistance generally declined as distance from the track increased.

No exposed soil was found in the tracks where mulching occurred. Where no mulching occurred in tracks there was $9 \%$ bare soil compared to approximately $6 \%$ in a nearby native grass area. As expected, the estimated overall

\begin{tabular}{lrrrr}
\multicolumn{1}{l}{ TABLE 2. Pairwise t-tests for penetrometer data* } \\
\hline \multicolumn{1}{l}{ Depth } & Transect & \multicolumn{1}{c}{$\boldsymbol{T}$-value } & df & $\boldsymbol{P}$ \\
\hline 2 inches & $0-10$ feet & 0.6817 & 14 & 0.5065 \\
& $10-20$ feet & -1.0236 & 14 & 0.3234 \\
& $0-20$ feet & -0.2644 & 14 & 0.7953 \\
\hline 4 inches & $0-10$ feet & 0.5169 & 14 & 0.6133 \\
& $10-20$ feet & 1.0744 & 14 & 0.3008 \\
& $0-20$ feet & 2.3218 & 14 & 0.0358 \\
\hline 6 inches & $0-10$ feet & 1.5787 & 13 & 0.1384 \\
& $10-20$ feet & -0.1172 & 11 & 0.9088 \\
& $0-20$ feet & 1.3864 & 11 & 0.1931 \\
\hline inches & $0-10$ feet & -0.2736 & 7 & 0.7923 \\
& $10-20$ feet & 0.3332 & 6 & 0.7503 \\
& $0-20$ feet & 1.7085 & 6 & 0.1384 \\
\hline 10 inches & $0-10$ feet & 0.7923 & 6 & 0.4583 \\
& $10-20$ feet & 0.3332 & 6 & 0.7503 \\
& $0-20$ feet & $\mathbf{2 . 3 4 4 6}$ & $\mathbf{8}$ & $\mathbf{0 . 0 4 7 1}$ \\
\hline
\end{tabular}

* Significant differences at $>95 \%$ level in bold.

forest-stand density was visibly lower, while the sky-view factor was greater in the masticated area when compared to an adjacent untreated area.

Results from the cone penetrometer measurements suggested that the use of heavy mastication machinery did not result in significant compaction at most soil depths, regardless of the distance from the machine tracks. At the 4-inch (10-centimeter) depth, the significant increases in soil strength that occurred were likely due to the machine travel. Reasons for the significantly increased compaction at the 10-inch (25-centimeter) depth are not clear. However, it is likely that the change in textural and organic content associated with a typical Tallac series soil, where organic carbon falls from $4.85 \%$ to only $2.17 \%$ below about 5 inches (13 centimeters), may play a key role since higher organic carbon content is associated with a greater propensity toward soil deformation or less resistance.

Assuming that machine use increases overall soil compaction, we would expect a trend of increased compaction across all depths of the soil at all distances from the track. However, no significant increases in compaction were found between the machine track and the 10-foot (3-meter) distance; the only significant increases were between the machine track and the 20-foot (6.1-meter) distance. This suggests that any compaction due to machine use is detectable only when comparing soil strength in the actual path of the machine to much-lessdisturbed soil distant from any machine travel. That is, soil compaction appears not to be highly localized but rather is 


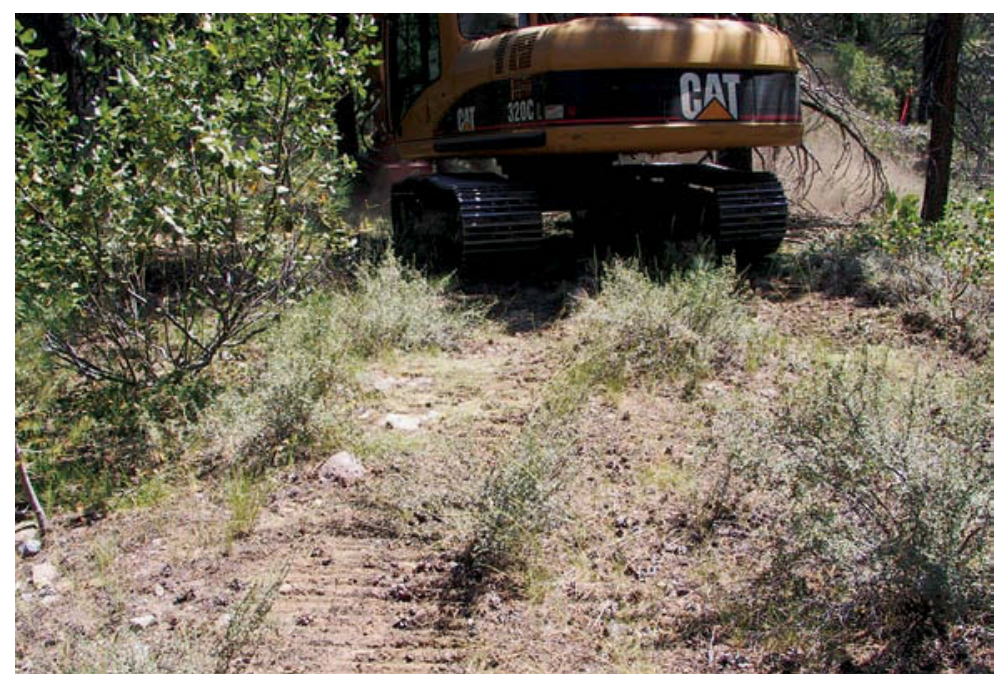

Above, runoff from masticated sites with granitic soils were much more likely to contain certain sizes of sediment particles than those from volcanic soils. Right, forests in the Tahoe Basin are severely compromised by the suppression of wildfires, disease and insect stress.

dispersed gradually over a large distance so that significant increases occur only when extreme distances are compared.

\section{Rainfall doesn't increase erosion}

Results from the rainfall simulator tests indicated that regardless of the surface treatment, erosion and runoff rates depended largely on whether the soils were of granitic or volcanic origin. This observation was supported by particlesize analyses of bulk soil samples collected from the project site. We characterized the particle-size distributions using the maximum size $\left(D_{\mathrm{xx}}\right)$, corresponding to the percentage of particles less than that size. For example, the $\mathrm{D}_{50}$ particle size is the median, with $50 \%$ of the particles larger and 50\% smaller; similarly, $10 \%$ of the soil particles are smaller than the $\mathrm{D}_{10}$ size. $\mathrm{D}_{10}, \mathrm{D}_{30}$ and $\mathrm{D}_{60}$ particle sizes are often used in geotechnical engineering studies to estimate infiltration rates. Generally, the larger the particles in a soil, the greater the infiltration rates.

We found that the mean $\mathrm{D}_{10}, \mathrm{D}_{30}$ and $\mathrm{D}_{60}$ particle sizes of granitic soils in the Tahoe Basin were approximately twice those of the volcanics (table 3). As expected from the site description, soil particle sizes from the masticator treatment site fell between those from other granitic and volcanic soils, although they were more similar to other granitic soils in the basin (Grismer and Hogan 2005). Thus, we expected infiltration rates at the site to be somewhat less than that from other granitic soil sites, but much greater than that from volcanic soils sites.

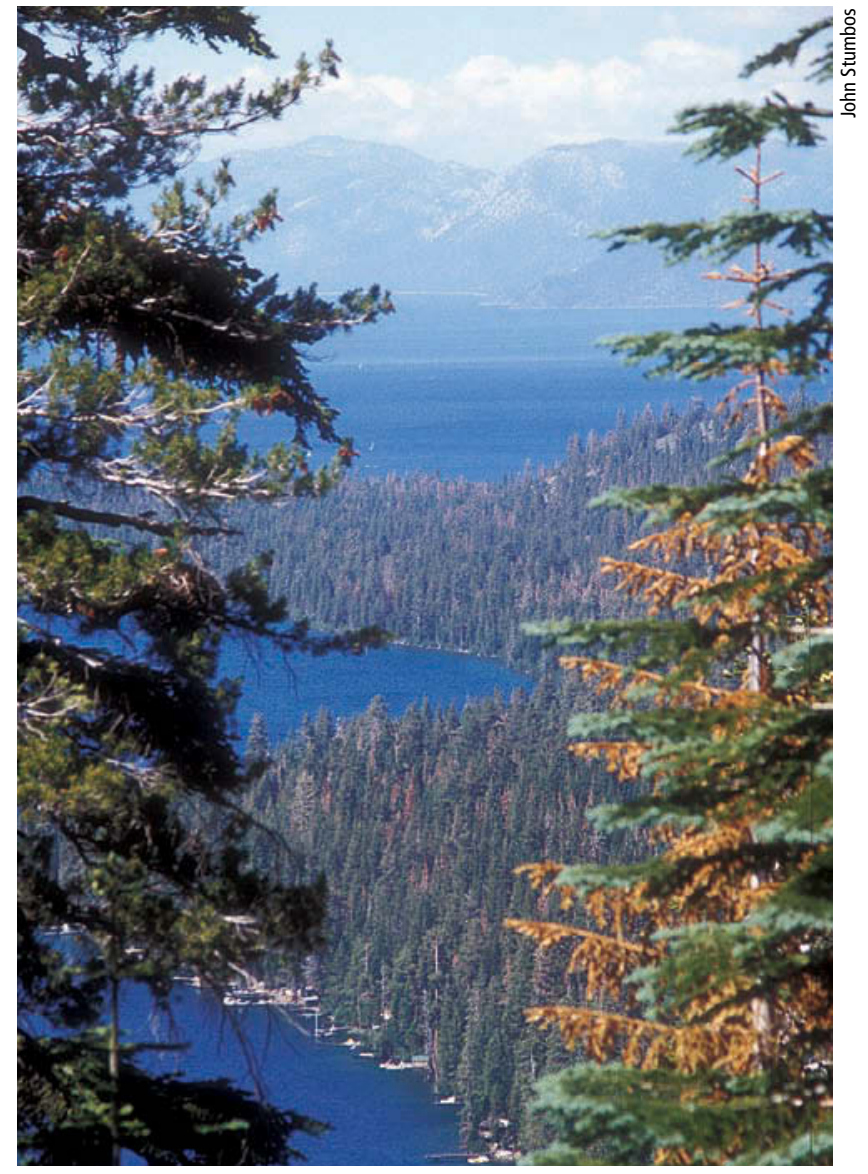

Also as expected, sediment yields were greatest from the bare soil plots, although one of the bare plots had unusually deep soil and did not generate any runoff. Slope angles were quite similar between different treatment plot averages (table 4). No runoff was generated from any of the native grass or woodchipcovered plots, or from the undisturbed (native) plots at the normal rainfall rate of 2.9 inches per hour (73 millimeters per hour). This result suggests that for rainfall events as high as three times the 20-year, 1-hour storm sometimes used to design stormwater runoff structures in the basin, there is no runoff from woodchip-mulched mastication sites with slopes of up to about 20\%. Higherintensity rainfall (4.7 inches or 120 millimeters per hour) did generate runoff from these plots, resulting in sediment yields from the woodchip, grass cover and native plots that were $32 \%, 24 \%$ and $9.5 \%$, respectively, of that from the bare soil. Not surprisingly, organic matter fractions were about $60 \%$ greater in the runoff sediment trapped on the filters in the lab (rather than soil minerals) in the woodchip, grass cover and native soil plots than in that from the bare soils. It should be noted that such high-intensity (4.7 inches per hour) rain events of 15-minute durations are extremely rare in the Tahoe Basin.

Particle-size distributions in the runoff samples collected during the rainfall simulations from all plots were similar to those from other granitic soils, consistent with the particle-size measurements of the bulk soil samples collected (table 5). Runoff particle sizes from the woodchip plots were much larger than those from the bare, native and grass cover soils, suggesting that masticated woodchips may be an effective control for the small par-

TABLE 3. Particle-size distribution measurements for disturbed granitic and volcanic soils in the Tahoe Basin (size fractions)

\begin{tabular}{|c|c|c|c|c|c|}
\hline Soils & $n$ & $\mathrm{D}_{10}$ & $D_{30}$ & $D_{60}$ & $\mathrm{D}_{90}$ \\
\hline \multicolumn{6}{|l|}{ Granitic } \\
\hline Mean & 33 & 117.06 & 322.48 & 946.36 & ND \\
\hline Std. deviation (CV \%) & 33 & $20.4(17.4)$ & $73.9(22.9)$ & $208(22.0)$ & ND \\
\hline \multicolumn{6}{|l|}{ Volcanic } \\
\hline Mean & 28 & 4.62 & 16.37 & 37.68 & 68.64 \\
\hline Std. deviation (CV \%) & 28 & $0.99(21.5)$ & $2.63(16.1)$ & $5.83(15.4)$ & $9.31(13.6)$ \\
\hline
\end{tabular}


TABLE 4: Averages of measured parameters from rainfall-simulator plots on Tahoma masticator site soils

\begin{tabular}{|c|c|c|c|c|c|c|c|c|c|c|c|}
\hline \multirow[b]{2}{*}{ Treatment } & \multicolumn{2}{|c|}{ Slopes } & \multirow{2}{*}{$\begin{array}{l}\text { Time to } \\
\text { runoff }\end{array}$} & \multicolumn{2}{|c|}{$\begin{array}{c}\text { Cumulative value } \\
\text { @ } 15 \mathrm{~min} .\end{array}$} & \multicolumn{4}{|c|}{ Steady } & \multirow[b]{2}{*}{ Sed. yield } & \multirow[b]{2}{*}{$\mathbf{R}^{2}$} \\
\hline & Down & Cross & & Runoff & Sed. & Infiltration & Runoff & S. conc. & OM & & \\
\hline & \multicolumn{2}{|c|}{$\ldots \ldots \% \ldots$} & $\sec$ & $m m$ & $g$ & $m m / h r$ & \multicolumn{2}{|c|}{$\ldots \ldots g / L \cdots \ldots$} & $\%$ & $\mathrm{~g} / \mathrm{mm}$ & $\%$ \\
\hline \multicolumn{12}{|l|}{ Normal (2.9 in/hr) } \\
\hline Bare soil & 16.47 & 12.43 & 369 & 0.70 & 1.12 & 59.77 & 13.23 & 0.91 & 14.3 & 1.48 & 89.49 \\
\hline Woodchips & 19.05 & 12.13 & No runoff & & & & & & & & \\
\hline Grass cover & 13.49 & 7.20 & No runoff & & & & & & & & \\
\hline Native (undisturbed) & 15.48 & 9.43 & No runoff & & & & & & & & \\
\hline \multicolumn{12}{|c|}{ High-intensity $(4.7 \mathrm{in} / \mathrm{hr})$} \\
\hline Woodchips & 23.42 & 13.60 & 364 & 1.84 & 0.91 & 103.55 & 16.45 & 0.76 & 23.14 & 0.48 & 97.92 \\
\hline Grass cover & 17.07 & 8.41 & 125 & 6.48 & 1.97 & 87.23 & 32.77 & 0.24 & 21.50 & 0.36 & 84.14 \\
\hline Native (undisturbed) & 15.48 & 9.61 & 136 & 2.80 & 0.28 & 111.84 & 12.41 & 0.04 & 24.28 & 0.14 & 79.05 \\
\hline
\end{tabular}

ticles that are associated with declining water clarity in Lake Tahoe (see page 49).

As observed elsewhere in the basin, native grass cover and the incorporation of woodchips dramatically reduce sediment loss. Rainfall simulations at this site were taken less than one season after mastication; additional assessments will be useful and are anticipated. In areas like our study site, where topsoil remains and is only slightly disturbed, impacts 1 to 3 years later may be quite different than during the first season following mastication treatment.

\section{Benefits of mastication}

Our results suggest that erosion is slight to insignificant following mastication, provided that a layer of woodchip mulch is left on the forest floor and the mastication equipment is operated in an environmentally effective manner. The resulting thickly mulched litter layer may offset any increased erosion potential that results from the limited soil compaction that may occur. In addition, any decrease in the potential for root growth due to compaction should be offset by the renewed vigor of growth in the stand due to thinning. Indeed, the combination of a mulched layer and thinning has the potential to decrease erosion and increase overall stand health.

While some have suggested that mastication has a high potential for ground compaction and increased erosion, our study clearly showed that this is the case only when bare ground is present. From a watershed perspective, sediment moving from bare areas is likely to be captured in more heavily mulched areas. However, our study only considered conditions at the site one winter season following mastication; long-term impacts are unknown.

Ultimately, the decision to use specific practices for improving forest health will depend on social, economic and environ-

TABLE 5. Particle-size distributions in runoff samples from rainfall-simulator masticator plots in the Tahoe Basin

\begin{tabular}{|c|c|c|c|c|c|}
\hline Treatment & $D_{10}$ & $D_{30}$ & $D_{50}$ & $D_{60}$ & $\mathrm{D}_{90}$ \\
\hline & & & & & \\
\hline Bare & 11.68 & 42.90 & 114.97 & 189.42 & 881.43 \\
\hline Grass & 11.40 & 39.07 & 78.47 & 116.93 & 666.00 \\
\hline Native & 10.77 & 32.07 & 73.77 & 123.67 & 713.00 \\
\hline Woodchips & 15.35 & 57.80 & 162.50 & 289.50 & $1,283.00$ \\
\hline
\end{tabular}

mental factors. Our results suggest that mastication may be a more time- and cost-effective method of forest thinning. Considering its relatively low or nonexistent environmental impacts, properly implemented mastication offers a potentially useful tool to achieve forest and watershed health goals.

B. Hatchett is Undergraduate Student, University of Nevada, Reno; M.P. Hogan is President, Integrated Environmental Restoration Services, Tahoma, Calif.; and M.E. Grismer is Professor, Departments of Land, Air and Water Resources, and Biological and Agricultural Engineering, UC Davis. We wish to thank the California Tahoe Conservancy for funding this study, the Meeks Bay Fire Protection District for their support in developing and implementing this project, and Stephen Hatchett for assistance with the statistical analyses.

\section{References}

Allred BW. 1950. Practical grassland management. Sheep Goat Raiser. San Angelo, TX.

Battany MC, Grismer ME. 2000. Development of a portable field rainfall simulator system for use in hillside vineyard runoff and erosion studies. Hydrologic Proc 14:1119-29.

Bonan G. 2002. Ecological Climatology. Cambridge, NJ: Cambridge Univ Pr. 678 p.

Bonham CD. 1989. Measurements for Terrestrial Vegetation. New York: J Wiley. $338 p$

Bowling L, Storck P, Lettenmaier D. 2000. Hydrologic effects of logging in western Washington, United States. Water Resour Res 36(11):3223-40.

Crocker RL, Tivner NS. 1948. Survey methods in grassland ecology. J British Grassl Soc 3:1-26.

Elzinga CL, Salzer DW, Willoughby JW. 1998. Measuring and Monitoring Plant Populations. US Government Printing Office, Washington, DC.
Eshel G, Levy GJ, Mingelgrin U, Singer MJ. 2004. Critical evaluation of the use of laser light scattering for particle-size distribution analysis. Soil Sci Soc America J 68:736-43.

Frisby J, Pfost D. 1993. Soil Compaction: The Silent Thief. Univ Missouri Ag Pub G1630. Univ MissouriColumbia Extension.

Grismer ME, Hogan MP. 2004. Evaluation of revegetation/mulch erosion control using simulated rainfall in the Lake Tahoe Basin: 1. Method assessment. Land Degradation Dev 13:573-88.

Grismer ME, Hogan MP. 2005. Evaluation of revegetation/mulch erosion control using simulated rainfall in the Lake Tahoe Basin: 2. Bare soil assessment. Land Degradation Dev 16:397-404.

Hogan M. 2003. Luther Pass Monitoring Report: Plant and Soil Cover Monitoring for Evaluating Sediment Source Control Success in the Lake Tahoe Basin. Lahontan Regional Water Quality Control Board. South Lake Tahoe, CA

Imeson AC, Lavee H. 1998. Soil erosion and climate change: The transect approach and the influence of scale. Geomorphol 23:219-27.

Landsberg J, Miller R, Anderson H, Tepp J. 2003. Bulk Density and Soil Resistance to Penetration as Affected by Commercial Thinning in Northeastern Washington. Res Pap PNW-RP-551. USDA Forest Service, Pacific Northwest Research Station, Portland, OR. 35 p.

Molinar RF, Galt D, Holechek J. 2001. Managing for mulch. Rangelands 23(4):3-7.

Munn J. 1998. Angora Highlands Mastication Project Compaction Study. California Dept Forestry and Fire Protection Res Pap. 12 p

Nolte BH, Fausey NR. 1986. Soil Compaction and Drainage. Ohio State Univ Extension AEX 301.

Radcliffe DE, Rasmussen TC. 2000. Soil water movement. In: Sumner ME (ed.). Handbook of Soil Science. Boca Raton, FL:CRC Pr. p A87-128.

Rogers JH. 1974. Soil Survey of the Tahoe Basin Area, California and Nevada. US Government Printing Office, Washington, DC.

Wall G, Baldwin C, Shelton I. 1987. Soil Erosion Causes and Effects. Ontario Ministry of Agriculture and Food Factsheet Agdex\# 572.

Wilson D. 1992. Sawdust Trails in the Truckee Basin: A History of Lumbering Operations. Nevada County Historical Society, Nevada City, CA. 